\title{
Signatures of Wetland Impact: Spatial Distribution of Forest Aboveground Biomass in Tumen River Basin
}

\author{
Guanting Lv ${ }^{1,2}$, Guishan Cui ${ }^{1,2, *}$, Xiaoyi Wang ${ }^{2}{ }^{-}$, Hangnan Yu ${ }^{1}$, Xiao Huang ${ }^{1}$, Weihong Zhu ${ }^{1}$ and Zhehao Lin ${ }^{1}$ \\ 1 College of Geography and Ocean Sciences, Yanbian University, Yanji 133002, China; \\ guantinglv@itpcas.ac.cn (G.L.); 0000008657@ybu.edu.cn (H.Y.); 2019010414@ybu.edu.cn (X.H.); \\ whzhu@ybu.edu.cn (W.Z.); zhlin@ybu.edu.cn (Z.L.) \\ 2 Key Laboratory of Alpine Ecology, Institute of Tibetan Plateau Research, Chinese Academy of Sciences, \\ Beijing 100085, China; xiaoyiwang@itpcas.ac.cn \\ * Correspondence: cuiguishan@ybu.edu.cn; Tel.: +86-138-4338-1515
}

check for

updates

Citation: Lv, G.; Cui, G.; Wang, X.; Yu, H.; Huang, X.; Zhu, W.; Lin, Z. Signatures of Wetland Impact: Spatial Distribution of Forest Aboveground Biomass in Tumen River Basin. Remote Sens. 2021, 13, 3009. https:// doi.org/10.3390/rs13153009

Academic Editors: Cholho Song, Chul-Hee Lim, Woo-Kyun Lee, Jay Sagin and Hadi

Received: 1 July 2021

Accepted: 27 July 2021

Published: 30 July 2021

Publisher's Note: MDPI stays neutral with regard to jurisdictional claims in published maps and institutional affiliations.

Copyright: (c) 2021 by the authors. Licensee MDPI, Basel, Switzerland. This article is an open access article distributed under the terms and conditions of the Creative Commons Attribution (CC BY) license (https:// creativecommons.org/licenses/by/ $4.0 /)$.

\begin{abstract}
The Tumen River Basin, located in the cross-border region of China, North Korea, and Russia, constitutes an important ecological barrier in China. Forest here is mainly distributed around wetland, with the distribution of wetland having the potential to regulate regional forest carbon storage. However, the spatially explicit map of forest aboveground biomass (AGB) and potential impact of drivers, i.e., wetland distribution and climate, is still lacking. We thus use a deep neural network and multi-source remote sensing data to quantify forest AGB in the Tumen River Basin. Our results show the mean forest AGB is $103.43 \mathrm{Mg} \mathrm{ha}^{-1}$, with divergent spatial variation along its distance to wetland. The results of correlation analysis showed that with sufficient soil moisture supply, temperature dominant spatial variation of forest aboveground biomass. Noted that using the space for time substitution, we find when wetland decreased by less than $11.1 \%$, the forest AGB decreased by more than $8 \%$. Our result highlight the signatures of wetland impact on its nearby forest carbon storage, and urge the wetland protection, especially under the warming and drying future.
\end{abstract}

Keywords: forest aboveground biomass; climate change; degradation of wetland; deep learning

\section{Introduction}

Wetland is one of the important terrestrial ecosystems, providing a variety of ecosystem services globally and regionally [1,2], including regulating hydrological processes, maintaining biodiversity, and regulating the carbon sequestration of wetland vegetation, etc. [3]. The flooded environment of wetland soil plays an important role in maintaining the ecological balance at the basin scale [4]. However, since 1970, the area of wetlands in the world has been drastically reduced [5,6], and about $50 \%$ of the wetlands have been eliminated [7], causing serious ecological and social problems [7]. Numerous studies have shown that changes in the hydrothermal conditions caused by the large-scale degradation of wetlands affect the functions of the ecosystems around the wetlands and their sensitivity to climate factors [8-11].

Forest aboveground biomass (AGB) refers to the mass of the aboveground portion of a forest within a given range, which is generally twice as large as the carbon stock, and it is the basis for measuring ecosystem function and structure [12], and plays a vital role in the assessment of global carbon cycle and climate change [13]. Studies have shown that forest vegetation stores nearly $80 \%$ of the biomass of the terrestrial ecosystem [14,15], and the carbon flux between forest vegetation and the atmosphere accounts for $90 \%$ of the entire terrestrial ecosystem [16]. Therefore, forest AGB is not only an important carbon pool in the global carbon cycle, but also an important indicator for assessing the potential carbon sink. It is worth noting that the forest AGB is very sensitive to hydrothermal conditions. The most obvious feature is that the forest AGB has large regional differences and large inter-annual fluctuations. For example, in the conclusion of $\mathrm{Hu}$ et al. (2016) [17], there is a 
13.45 $\mathrm{Mg} \mathrm{ha}^{-1}$ difference in forest AGB between humid regions $\left(157.69 \mathrm{Mg} \mathrm{ha}^{-1}\right)$ and dry regions $\left(171.41 \mathrm{Mg} \mathrm{ha}^{-1}\right)$.

For forest ecosystems in the inland wetland environment, the degradation of inland wetlands affects the reduction or closure of vegetation stomatal conductance, transpiration, and photosynthesis [18], and vegetation productivity by reducing soil available water [19]. On the other hand, the reduction in soil moisture will intensify the forest's stress on soil moisture [20,21], and then affect the sensitivity of forest AGB to climate factors. Due to the limited adaptability of forest ecosystems, the degradation of inland wetlands is likely to cause the severing of, and long-lasting and irreversible damage to, forest ecosystems. Therefore, how to comprehensively and accurately understand the impact of inland wetlands on forest ecosystems is a general concern in the current carbon cycle research.

Accurate monitoring of forest AGB is the basis for in-depth research on forest ecosystems. At the regional scale, the remote sensing estimation method is the only feasible means to achieve large-scale monitoring at different scales, and it is one of the more commonly used methods for forest AGB estimation [22]. Normalized vegetation index (NDVI) is currently the most commonly used method for monitoring AGB of large-scale forests. This index has been widely used in establishing forest biomass models [23] and extracting forest targets [24]. However, the traditional estimation of forest biomass based on the linear relationship method is subject to a series of reasons, such as the limitation of the reflection wavelength of multispectral remote sensing images, and the NDVI value may be saturated in the dense forest estimation [25]. Moreover, in areas with a high proportion of water bodies, the spectral reflectance of remote sensing may also be affected by water body signals, which will increase the uncertainty of NDVI calculations.

The construction of machine learning algorithms not only includes linear relationship parameters but also realizes the application of non-linear parameter datasets. It can be said that machine learning algorithms have improved the accuracy of traditional band combinations to a certain extent [26]. The deep neural networks (DNN) algorithm is developed from the deep learning algorithm of the machine learning model. This method deepens the depth of the hidden layer and overcomes the phenomenon that the classification results of a traditional perceptron are insufficient to solve complex problems. In particular, the current DNN not only adds a variety of non-linear activation functions but also adds a regularization term, which optimizes the performance of the deep provincial network. In addition, neural network models with different functions can be supervised according to different actual problems.

At the regional or global scale, most researches focus more on the model's ability to estimate forest biomass, and the research areas are mostly concentrated in tropical regions. There are few studies on the distribution structure of forest AGB on the watershed scale, and the impact of inland wetland degradation on forest AGB is still lacking in a systematic and in-depth understanding. The Tumen River is an international river located at the junction of China, North Korea, and Russia. It is the only water passage from inland China to the Sea of Japan. This area plays an important role in the three river source areas of Northeast China. In addition, the Tumen River Basin has a relatively high forest coverage rate, which is the only horizontal zonal area of vegetation in China with relatively complete natural community fragments and has a relatively unique wetland hydrothermal environment [27]. However, the impact of the substantial reduction in the wetland area in the basin on the forest AGB is still less concerned, and the understanding is relatively scattered. Therefore, it is of great scientific significance to quantitatively analyze the distribution structure of forest AGB in the Tumen River Basin and deeply understand the impact of rivers, swamps, and other inland wetland types on forest AGB.

This study used a DNN method to quantify the distribution structure of forest AGB and explores the impact of inland wetland degradation on forest AGB in the Tumen River Basin (Figure 1). This research is expected to improve the understanding of the protection of wetland forest ecosystems at the basin scale and provide an important theoretical basis for the establishment of regional ecosystem models. 


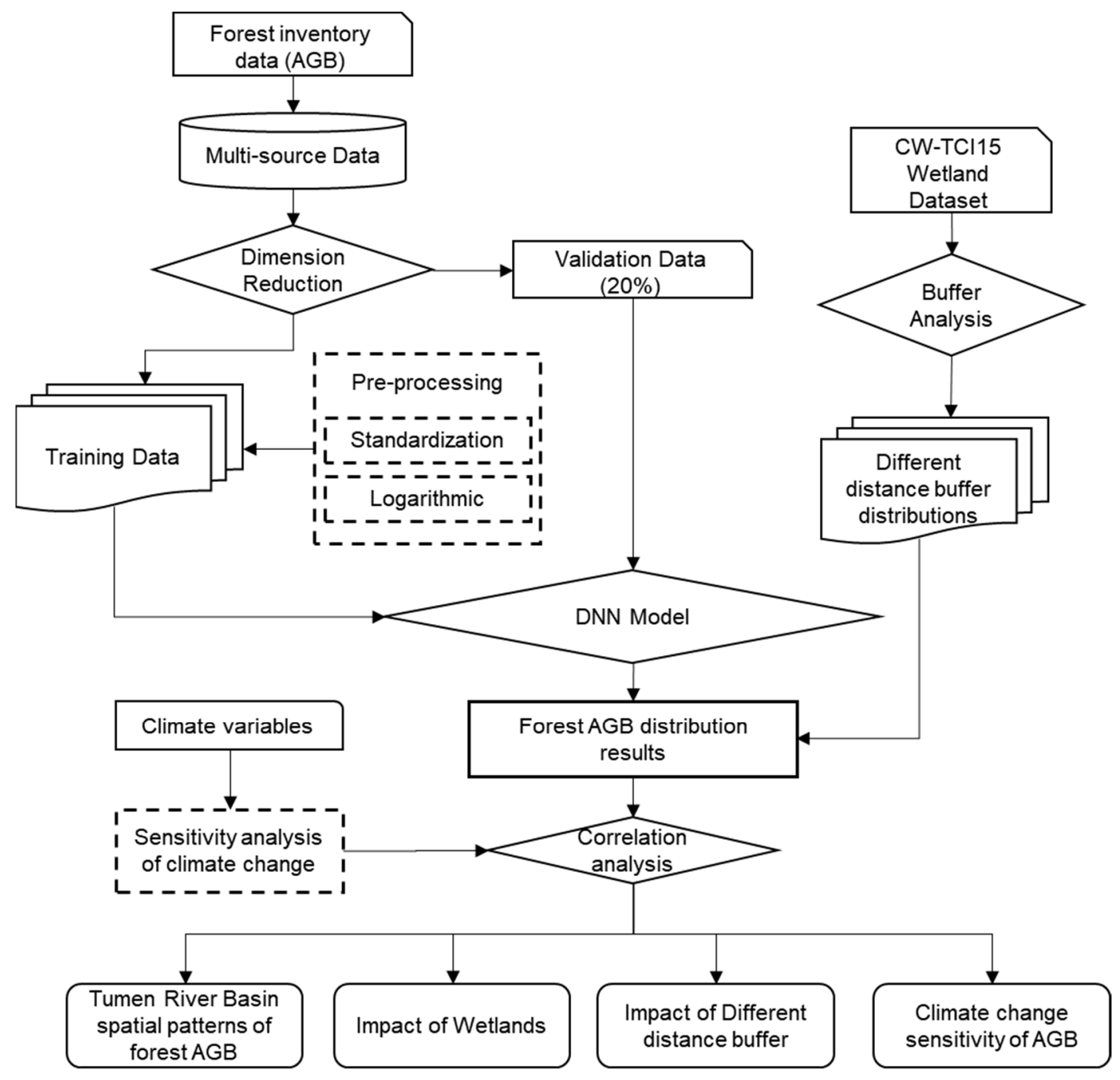

Figure 1. The framework of this study.

\section{Materials and Methods}

\subsection{Study Site}

The Tumen River Basin is located at the junction of China, North Korea, and Russia, and belongs to the mid-temperate continental monsoon zone. The area is dominated by wetland ecosystem, with an area of $903.66 \mathrm{~km}^{2}$ [28], which is an important wetland forest in the forest ecosystem of northeast China. It is also the most characteristic area of forest ecological environment in the Changbai Mountain area (Figure 2). The area is close to the Sea of Japan and is affected by the ocean climate. The climate in this area is mild, the annual temperature difference is small, and the rainfall is sufficient. Therefore, the forest and vegetation coverage in this watershed is relatively high, with a forest coverage rate of $76 \%$. 


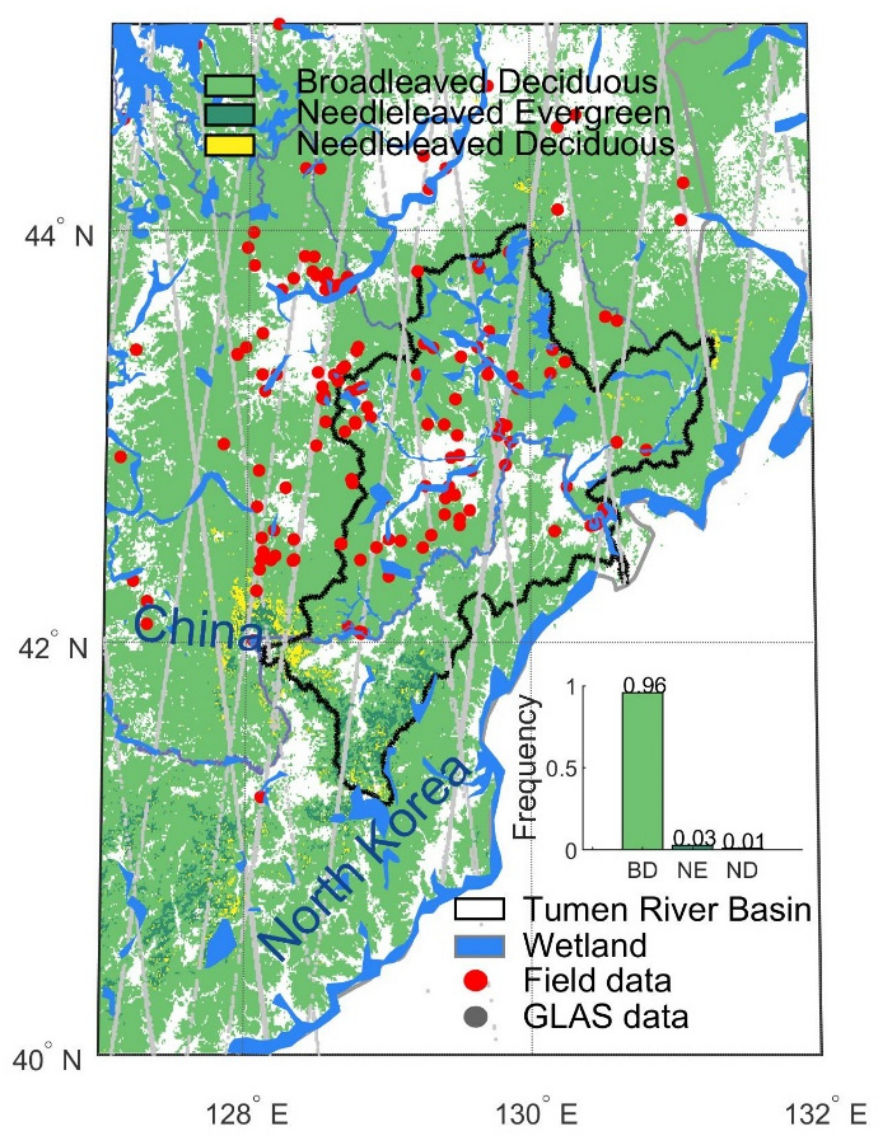

Figure 2. The forest type and wetland distribution of ESA CCI land cover data in the Tumen River Basin, where the red dots represent the location information of the measured sample points, and the gray dots represent the GLAS footprint trajectory.

\subsection{Modeling}

\subsubsection{Field Data}

When building the model, we added two related types of training data. Firstly, we collected 180 sample site inventory data with reference to the previous literature. Each data maintained the consistency of the research at the sample site scale, and followed the principle of sample site measurement to ensure that the collected data were not subject to human interference during the collection period. Finally, all field data are AGB of mature forest containing the coordinates of the center point of the sample plot. The distribution of these data samples in the study area is shown in Figure 2.

Another type of training data is obtained from the Geoscience Laser Altimeter System (GLAS) instrument on NASA's Ice, Cloud, and Land Elevation (ICESat) satellite. We selected the data of L3J and L3K campaigns that are consistent with the sample data collection time and used it as additional training data to participate in the construction of the model. When screening the GLAS data, we removed cloud cover and other noise interference, and footprint points with large errors due to terrain factors, and deleted the value of non-forest locations, and finally attained 1714 footprint points that meet the requirements.

\subsubsection{Remote Sensing Data}

We obtained remote sensing images of Landsat data used for model training in 2015 from the Google Earth engine (accessed on: https: / / code.earthengine.google.com, accessed 29 July 2020) and in the pre-processing, we selected image data that at the time point with the best vegetation growth in the study area, and modeled the band values shown in Table 1 as five feature vectors in the model training data. 
Table 1. Landsat bands.

\begin{tabular}{ccc}
\hline & Name & Wave Length $(\mu \mathrm{m})$ \\
\hline Band1 & Green & $0.52-0.60$ \\
Band2 & Red & $0.63-0.69$ \\
Band4 & Near infrared red & $0.76-0.90$ \\
Band5 & Shortwave infrared red & $1.55-1.75$ \\
Band7 & Shortwave infrared red & $2.08-2.35$ \\
\hline
\end{tabular}

\subsubsection{Climate Data}

High-resolution climate data based on the Earth's land surface (CHELSA) (Accessed on: http:/ / chelsa-climate.org/, accessed 29 July 2020) is used for the climate feature data, and 17 standardized bioclimate variables (Table 2) are calculated as climate factors.

Table 2. CHELSA Bioclimate Variable.

\begin{tabular}{cc}
\hline & Name \\
\hline Bio1 & Annual Mean Temperature \\
Bio4 & Temperature Seasonality \\
Bio5 & Max Temperature of Warmest Month \\
Bio6 & Min Temperature of Coldest Month \\
Bio8 & Temperature Annual Range \\
Bio9 & Mean Temperature of Wettest Quarter \\
Bio10 & Mean Temperature of Driest Quarter \\
Bio11 & Mean Temperature of Warmest Quarter \\
Bio12 & Mean Temperature of Coldest Quarter \\
Bio13 & Annual Precipitation \\
Bio14 & Precipitation of Wettest Month \\
Bio15 & Precipitation of Driest Month \\
Bio16 & Precipitation Seasonality \\
Bio17 & Precipitation of Wettest Quarter \\
Bio18 & Precipitation of Driest Quarter \\
Bio19 & Precipitation of Warmest Quarter \\
& Precipitation of Coldest Quarter
\end{tabular}

In addition to the characteristics of biometeorological variables, we used additional CRU climate data to analyze the climate elements that control the distribution of forest AGB in the study area. The multi-year average of annual average precipitation, annual average precipitation and soil moisture before and after 2015 are used as climate variables, mainly to explore the relationship between forest AGB and precipitation or temperature in the Tumen River Basin. The distribution of temperature and precipitation in the Tumen River Basin is roughly the same as the global climate distribution.

\subsubsection{Other Data Sources}

Taking into account the influence of terrain factors on the forest AGB, we used the altitude and slope from Space Shuttle Radar Terrain Mission (SRTM, (Available online: https: / / srtm.csi.cgiar.org/download/, accessed 29 July 2020)) were used to train the forest AGB's adaptability to the terrain in the model. Meanwhile, we used Landsat data to calculate the normalized difference vegetation index (NDVI) to characterize vegetation coverage. In addition, to illustrate the distribution of AGB of different vegetation types in the Tumen River Basin, we also used ESA CCI land use data to divide the range and location of different tree species. 


\subsection{AGB Estimation Model}

\subsubsection{Processing Training Data}

This research uses random sampling method to divide the existing forest AGB data, select $80 \%$ of the data as the model training data, $10 \%$ as the test data, and the rest as the evaluation model verification data to verify the model.

\subsubsection{Model Prediction with the DNN Algorithm}

Using the Tensorflow framework developed by Google (Accessed on: https://tensorflow. google.cn/, accessed 29 July 2020), a fully connected DNN model is established under this framework to achieve the purpose of quantifying the AGB of wetland forests. This model is mainly composed of 4 hidden layers and 500 neurons in each layer. Each layer in the network will use the linear rectification unit (ReLU) function of the modified linear unit as the activation function. To avoid the problems of gradient explosion, gradient disappearance and overfitting, this study used the method of assigning weight attenuation (L2 regularization), dropout and early stopping. Finally, the optimal parameters of the model with a learning rate of 0.0002 and a training batch size of 50 are set to predict the forest AGB of the Tumen River Basin (See Table 3 for the specific structure of the model).

Table 3. DNN model structure.

\begin{tabular}{cc}
\hline Parameter & Weight \\
\hline Hidden layer & 4 \\
Number of Neure & 500 \\
Learning rate & 0.0002 \\
Epoch & 50 \\
Dropout & 0.4 \\
\hline
\end{tabular}

\subsubsection{Uncertainty Analysis of the Model}

In order to analyze the accuracy of DNN on the results of the forest AGB spatial distribution, we used the Bootstrap method to calculate the uncertainty of the results. The purpose is to eliminate the difference in the results of modeling using repeated sampling training data for 100 times, and the uncertainty fluctuations in the model during each training process, so as to illustrate the spatial distribution of the model's uncertainty in the AGB prediction.

\subsection{Spatial Distribution of Wetland in Tumen River Basin}

In the description of the range of wetlands, Tootchi et al. (2019) [28] constructed global wetland CWT data, which included non-humid areas, groundwater driven wetlands in TCI areas (GDWs-CI (15\%)), regular flooding wetlands (RFW), The intersection of RFWs and GDWs and five types of wetlands such as lakes (from HydroLAKES). We intercepted part of the Tumen River Basin for this article's exploration of wetlands

\subsection{The Impact of Inland Wetlands on Forest AGB}

In the sensitivity analysis, we select the 2015 CRU data annual average temperature, annual average precipitation, and soil moisture to calculate the partial correlation with the forest AGB of the Tumen River Basin. Partial correlation analysis can eliminate the impact of multiple factors on the efficiency of AGB. Here we mainly limit the temperature and precipitation (/soil moisture) calculate the correlation of forest AGB to soil moisture (/precipitation) and discuss forest AGB the effect of moisture control. 


\section{Results}

\subsection{Effects of Wetlands on Forest $A G B$}

\subsubsection{Relating Forest Canopy Height to AGB}

Due to the limited quantity of forest field measurement data in our study area, and after the quality screening, it is difficult to effectively carry out the prediction of forest $A G B$ in the study area with the measured data. Therefore, we use GLAS footprint data to expand the measured data and generate widely distributed forest $A G B$ sample data in the whole study area. Firstly, according to the information of forest canopy height $(\mathrm{H})$ and $A G B$ provided by the measured sample points, the unique allometric growth relationship between $\mathrm{H}$ and forest $A G B$ in the study area was established, then the functional relationship between the test points and AGBH in the measured forest data was calculated, and finally, the $A G B$ value corresponding to each GLAS point was obtained. The regression relationship of AGB-H was as follows

$$
A G B=1.56 \times H^{1.59}
$$

In Equation (1), the model explains $82 \%$ of the variance in $A G B$ field measurements and the standard error is $6.77 \mathrm{Mg} \mathrm{ha}^{-1}$. Based on the verification results, we believe that the relationship between $\mathrm{H}$ and $A G B$ established by the model can be used to expand the measured data from GLASs footprint data.

\subsubsection{Forest Biomass Mapping in Tumen River Basin}

In this study, we used DNN model combined with multi-source remote sensing data to estimate the forest $A G B$ of the Tumen River Basin. The 10-fold cross validation method was used to verify our results. The results are shown in Figure 3. The model finally obtained a higher $\mathrm{R}^{2}$ of 0.78 , and a lower RMSE of $4.21 \mathrm{Mg}$ ha $^{-1}$. The uncertainty is around $4 \%$. According to this verification result, our model has a good ability to capture regional forest $A G B$ and can effectively simulate regional forest $A G B$.

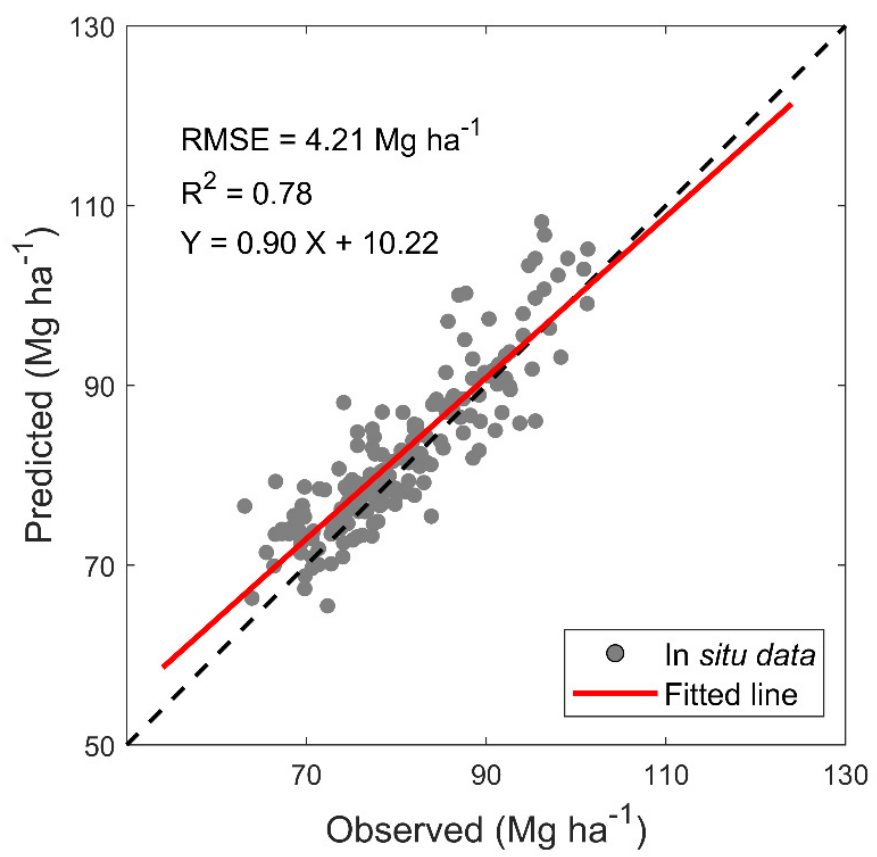

Figure 3. Verification of the model by dividing the validation data independent of the training data when using the training model. The red line represents the fitting curve that verifies the predicted and true values of the data. $\mathrm{R}^{2}$ and root-mean-square error (RMSE) of the validation results are used to evaluate our model. 
The spatial distribution of AGB in the Tumen River Basin Forest is shown in Figure 4. The regional average $\mathrm{AGB}$ value is $103.43 \mathrm{Mg} \mathrm{ha}^{-1}$, and the main distribution range is between 88.73 and $146.18 \mathrm{Mg} \mathrm{ha}^{-1}$ which represents $146.89 \pm 0.48 \mathrm{TgC}$ carbon storage. There are obvious differences in AGB between different tree types. The deciduous broad-leaved forest has a higher AGB accumulation value $\left(103.58 \mathrm{Mg} \mathrm{ha}^{-1}\right)$, while deciduous coniferous forest accounts for the least area in the study area, but average AGB $\left(102.62 \mathrm{Mg} \mathrm{ha}^{-1}\right)$ is second only to the deciduous broad-leaved forest. At the same time, the forest AGB in the Tumen River Basin also presents the characteristics of latitude distribution, with a significant increase and then decrease trend distribution as the latitude rises (Figure $4 \mathrm{~b}$ ). Between $42^{\circ} \mathrm{N}$ and $43^{\circ} \mathrm{N}$, the distribution of AGB reaches its peak. In addition, the forest AGB in the study area also showed a clear upward trend with the elevation gradient and reached a peak at $1000 \mathrm{~m}$. Through the uncertainty analysis results of bootstrap, it is found that the uncertainty of the DNN result is distributed in an altitude gradient. With the increase in altitude, the error of DNN's estimation of forest AGB also increases, and the distribution range is 2 to $16 \mathrm{Mg} \mathrm{ha}^{-1}$, within the interval $(p<0.01)$. Through the uncertainty calculation of Bootstrap, we evaluated the uncertainty of the final result after transmission in Figure 4d. The results show that the overall uncertainty of forest AGB in the Tumen River Basin is relatively low. However, there is a relatively high error at higher altitudes, which is caused by the data heterogeneity of GLAS footprint points in the high altitude rugged terrain.
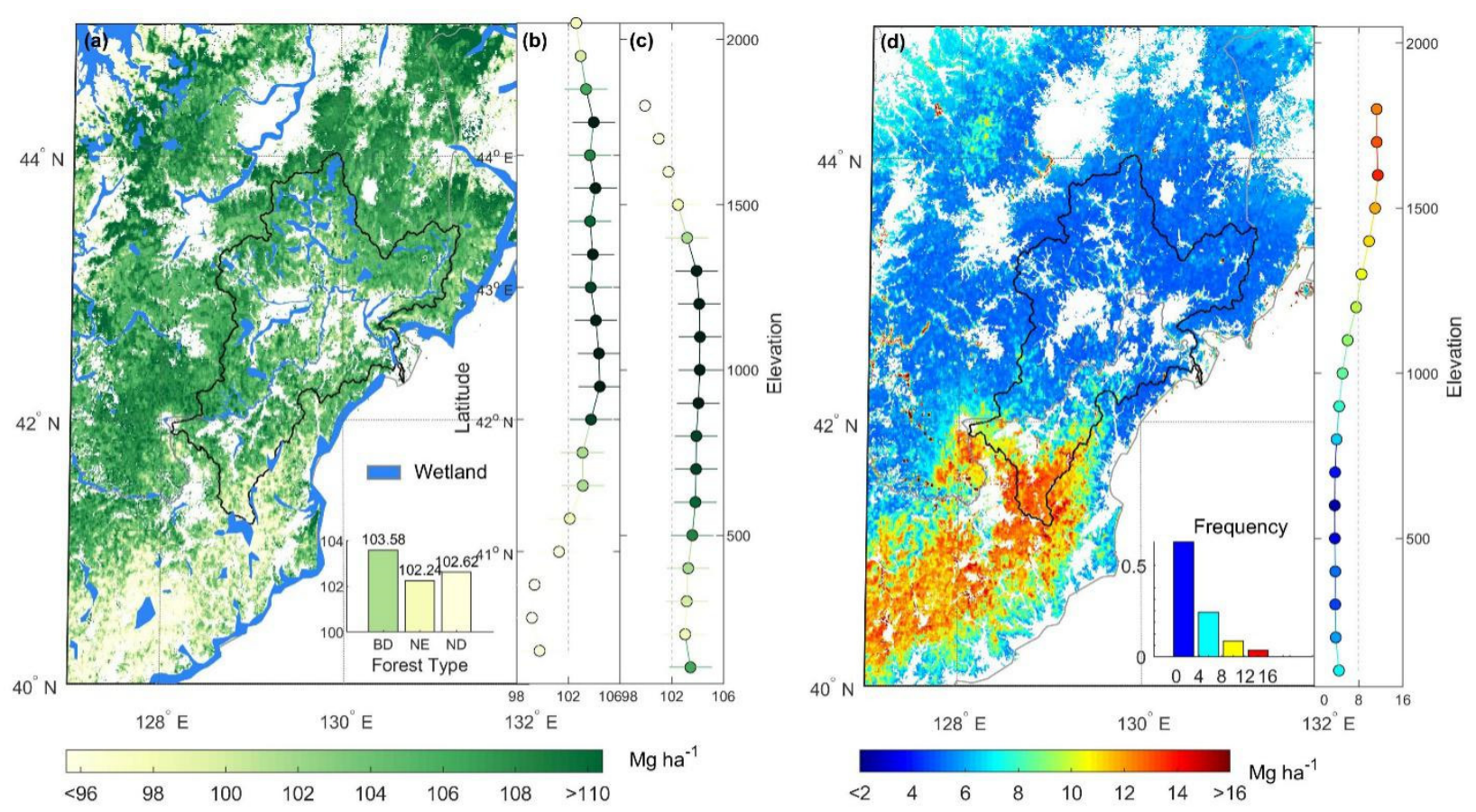

Figure 4. (a) The distribution of forest AGB in the Tumen River Basin in 2015, in which the inserted figure shows the average value of different vegetation types in the Tumen River Basin; (b) the distribution of forest AGB in the study area along the latitude gradient; (c) represents A line chart of the changes in the forest AGB along the elevation of the Tumen River Basin. (d) The distribution of uncertainty in Tumen basin and the uncertain distributions at different altitudes.

\subsection{Effects of Wetlands on Forest AGB Climate Sensitivity}

3.2.1. Control of Forest AGB in Wetland Area of Tumen River Basin by Climatic Factors

To explore the impact mechanism of climate change on the accumulation of forest AGB in the study area, we have drawn the climate spatial distribution map in Figure 5 to distinguish and analyze the control of temperature and precipitation on the forest AGB in the study area. The temperature range $\left(-5^{\circ} \mathrm{C}\right.$ to $\left.2.2^{\circ} \mathrm{C}\right)$ and precipitation range (557.79 to $1077 \mathrm{~mm}$ ) in the figure are the main impacts on the forest AGB of the Tumen River Basin. 
It can be seen from the figure that when the annual average temperature is lower than $-2{ }^{\circ} \mathrm{C}$, the forest AGB accumulation in the Tumen River Basin is almost unaffected by precipitation; and when the temperature is higher than $-2{ }^{\circ} \mathrm{C}$, the precipitation increased, the accumulation of AGB in the forests of the Tumen River Basin decreased slightly, and the variation range was within $1 \mathrm{Mg} \mathrm{ha}^{-1}$. However, when the precipitation is restricted and only the influence of temperature changes on the forest AGB changes in the study area is considered, it can be found that as the temperature rises, the forest AGB in the study area shows a clear increasing trend. It can be seen that in the spatial distribution of forest AGB in the Tumen River Basin, the accumulation of AGB is more sensitive to temperature changes, and when comparing the distribution of this trend on the altitude gradient, it can be seen that when the altitude is near $780 \mathrm{~m}$ in the range, temperature has the greatest control effect on forest AGB.

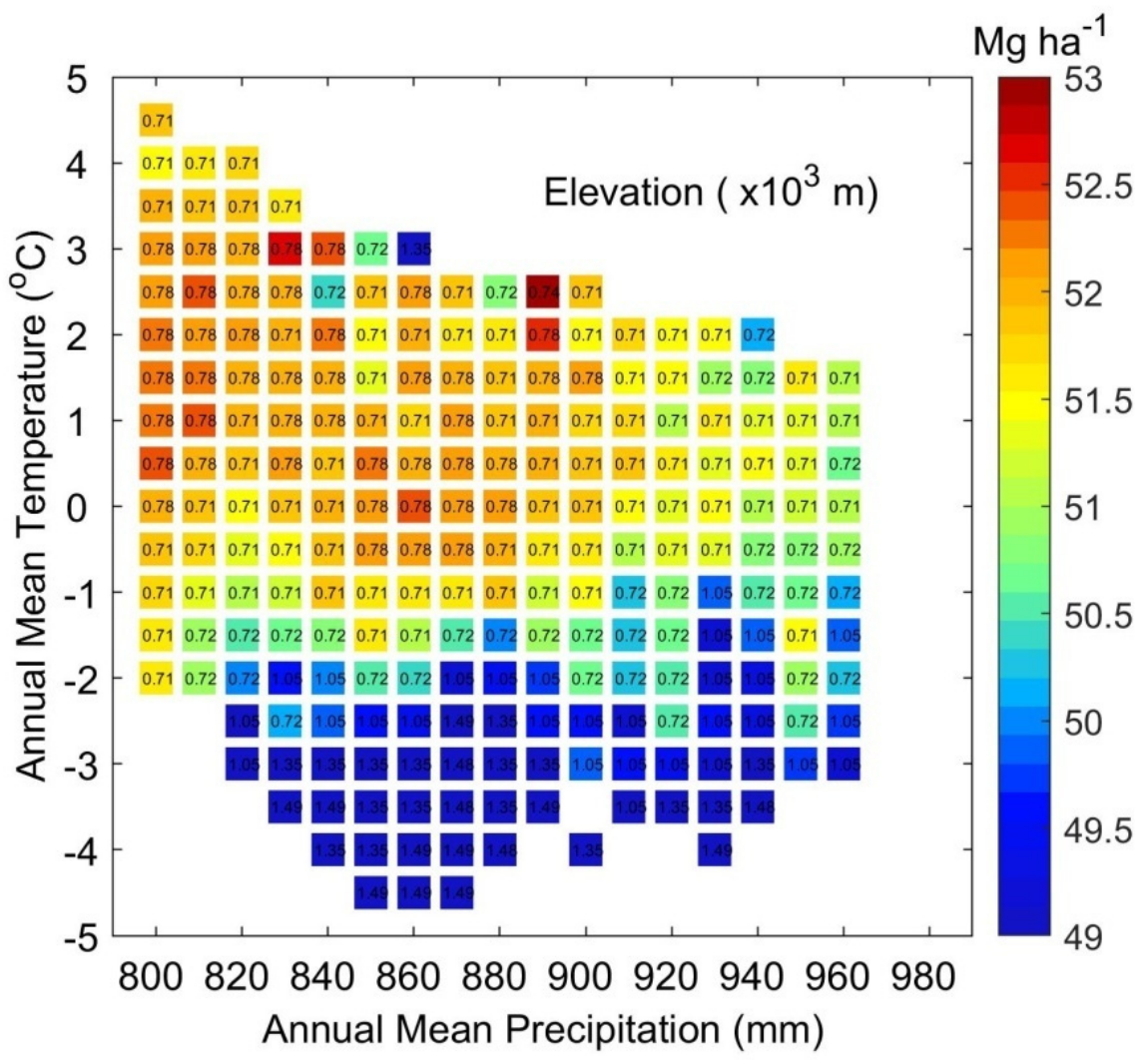

Figure 5. The spatial distribution trend of forest AGB under the combined influence of annual average temperature, annual average precipitation, and altitude gradient in the study area.

\subsubsection{Effects of Wetlands on Forest AGB}

Most of the current studies show that the accumulation of forest biomass is closely related to precipitation, especially in arid areas, which is almost not controlled by temperature. However, according to our results, the correlation between precipitation and forest AGB in Tumen River area is not significant. Therefore, we further explored the control effect of wetlands on forest AGB accumulation. We take the soil moisture as the moisture content.

Under the condition of controlling the effect of annual average temperature on forest AGB, the partial correlation between soil moisture and annual precipitation on forest AGB was calculated. Under the control of temperature and soil moisture, there was a weak negative correlation between precipitation and forest AGB $(R=-0.01, p>0.05)$. However, in controlling temperature and precipitation, only considering the correlation between soil moisture and forest AGB, we found that soil moisture had a significant positive effect 
on the accumulation of forest AGB. The results showed that soil moisture had a more significant effect on forest AGB accumulation than precipitation in Tumen River Basin.

\section{Discussion}

\subsection{Find a Suitable Method to Map the Biomass Distribution of Tumen River Basin}

Precisely predicting the vegetation biomass distribution in the wetland area is one of the challenges of biomass exploration. In general, using vegetation indices and empirical regression model methods [29] to estimate AGB usually results in a decrease in prediction performance due to the influence of data noise [30]. In this study, the DL method provided an important role for the accurate assessment of wetland forest AGB. Using the DNN method and combining a large number of predictive variables, such as remote sensing images, climate, and terrain-based data, this study obtained a reliable forest AGB $\left(4.17 \pm 0.47 \mathrm{Mg} \mathrm{ha}^{-1}\right)$ distribution in the Tumen River Basin (Table 4). The inter-level structure of the DNN model and the connection function of each component are more capable of explaining abstract regression problems; for example, using the L2 method to limit overfitting has a better performance compared to shallow machine learning models. Therefore, it has a good performance in eliminating the uncertainty of remote sensing data caused by special environmental influences.

Table 4. Average AGB values of different models at different distances from wetlands.

\begin{tabular}{cc}
\hline & DNN \\
\hline $\begin{array}{c}\text { Average AGB } \\
\left(\mathrm{Mg} \mathrm{ha}^{-1}\right) \\
\text { Range }\left(\mathrm{Mg} \mathrm{ha}^{-1}\right) \\
\text { Broadleaf Deciduous } \\
\left(\mathrm{Mg} \mathrm{ha}^{-1}\right)\end{array}$ & 103.62 \\
$\begin{array}{c}\text { Needleleaf Evergreen } \\
\left(\mathrm{Mg} \mathrm{ha}^{-1}\right)\end{array}$ & $88.73 \sim 146.18$ \\
$\begin{array}{c}\text { Needleleaf Deciduous } \\
\left(\mathrm{Mg} \mathrm{ha}^{-1}\right)\end{array}$ & 103.58 \\
\hline
\end{tabular}

\subsection{Wetlands Limit the Impact of Precipitation on Forest AGB}

For forest ecosystems, temperature and rainfall and seasonal patterns are important factors affecting forest growth [31]. However, the stress of different environmental factors on forest AGB also means that the complexity of its internal relationship increases. According to our climate-space mapping of the forests in the Tumen River Basin, the increase in precipitation may lead to a decrease in the AGB of the forests in this area. This is contrary to the study proposed by Fang et al. (2005) [32] that NDVI of deciduous broad-leaved forest in northeast China is positively correlated with annual precipitation. The reason for this phenomenon is that there are a large number of wetlands in the Tumen River Basin. Due to the existence of wetlands, the forests in this area are not sensitive to changes in precipitation. Through the analysis of the correlation between wetland and forest AGB, it is also proved that when the impact of wetland on the forest is excluded, precipitation has a weak positive correlation with forest AGB. This result is similar to the findings of Stegen et al. (2011) [33] in the study of tropical forests. In dry tropical and temperate forests, forest biomass increases with the driest season and annual precipitation, but in wet and temperate forests. In humid tropical forests, the impact of this change in precipitation on forest biomass is not clear.

In the past few decades, under the background of climate change, Northeast China has shown a trend of increasing temperature and decreasing precipitation [15]. However, according to our results, this trend may lead to an increase in forest AGB in the Tumen River Basin and promote the accumulation of carbon storage in the region. Therefore, under the trend of future climate change, the wetland is an important factor to protect the growth trend of forests from weakening due to the decline in precipitation. Therefore, the 
protection of wetland ecosystems can not only prevent wetland degradation but also play an important role in promoting forest growth and increasing carbon storage.

\subsection{Possible Impacts of Wetland Changes on the Tumen River Basin Forest AGB}

The results of correlation analysis between soil water content and forest AGB showed that the impact and feeding effect of wetland on the forest in its adjacent area was incomparable to that of water supply in other areas. Wetland degradation, resulting in the reduction of wetland area and the loss of ecosystem function, will simultaneously change the pattern of forest distribution and lead to the accumulation of forest biomass. Climate and environmental changes caused by wetland loss cannot be ignored [34]. Since the 1990s, the wetland area on the Chinese side of the Tumen River Basin alone has decreased by 19,560 ha, accounting for $40.54 \%$ of the total in the 1990s [35], and at the same time, the carbon storage on the forest ground also decreased by 10,000 Mg C between 1990 and 2015 [36].

By analyzing the correlation between wetland and forest AGB in the Tumen River Basin, the reduction in its wetland influence range will result in a decrease in the distance between the forest location and the wetland where the minimum AGB reached under the current environment. In this regard, our research is based on the scenario of increasing the scope of wetland influence and inferred the degradation of wetland in the wetland influence zone, that is, the reduction in the area corresponding to the distance from the wetland boundary, and the degree of impact on the forest AGB in the Tumen River Basin. The results are shown in Table 5. When the wetland area decreases by $1 \mathrm{~km}^{2}$ on average, the forest AGB accumulated in the Tumen River Basin will decrease by $0.074 \mathrm{Mg} \mathrm{ha}^{-1}$.

Table 5. Relationship between degraded area of wetland and forest accumulation reduction value.

\begin{tabular}{cc}
\hline Reduced Area $\left(\mathbf{k m}^{\mathbf{2}}\right)$ & Reduced AGB $\left.\mathbf{( M g ~ h a} \mathbf{~}^{\mathbf{1}}\right)$ \\
\hline 22.86 & 1.53 \\
34.45 & 2.44 \\
45.96 & 3.35 \\
57.42 & 4.22 \\
68.59 & 5.15 \\
79.26 & 6.06 \\
89.74 & 7.10 \\
100.17 & 8.29 \\
\hline
\end{tabular}

Therefore, under the background of achieving carbon neutrality in the country in 2060, maintaining the steady growth of forest carbon storage in the Tumen River Basin requires not only the protection of the forest in this area, but also the strengthening of the protection of the wetland ecosystem in the area to ensure the in the context of climate change, the forests in this area are growing steadily.

\section{Conclusions}

The forest ecosystem of the Tumen River Basin is unique in its geographical location, and the assessment of its forest AGB is an important part of the ecological environment assessment in both China and North Korea. The DNN model is used to estimate the forest AGB of the Tumen River Basin. The results show that the average AGB of the forest in the Tumen River Basin is $103.43 \mathrm{Mg} \mathrm{ha}^{-1}$, and its spatial distribution follows the law of changing with altitude and altitude. This phenomenon reflects the sensitivity of AGB to climate factors. The analysis results show that the forest ecosystem of the Tumen River Basin is unique in its geographical location, and the assessment of its forest AGB is an important part of the ecological environment assessment in both China and North Korea. The results show that the water restriction effect of wetlands on the forest AGB in the Tumen River Basin is greater than precipitation. Therefore, under the trend of drying in the northeast in the future, protecting the wetland's water replenishment barrier is an 
important direction to protect the stable development of forest carbon sinks in the Tumen River Basin under the current carbon neutral background. The results of this study provide a theoretical basis for discovering the link between forests and wetlands and studying the development trend of forest carbon storage.

Author Contributions: Conceptualization and methodology, G.L., G.C., X.W.; formal analysis, G.L., X.H.; writing—original draft preparation, G.L., G.C., X.W.; writing-review and editing, H.Y., W.Z. and Z.L. All authors have read and agreed to the published version of the manuscript.

Funding: This research was funded by NAME OF FUNDER, grant number 41977401, 41806227, 41830643, 20200802013GH.

Institutional Review Board Statement: Not applicable.

Informed Consent Statement: Not applicable.

Acknowledgments: This study was supported by National Natural Science Foundation of China (Grant 41977401, 41806227, 41830643, 20200802013GH).

Conflicts of Interest: The authors declare no conflict of interest.

\section{References}

1. Millennium Ecosystem Assessment. Ecosystems and Human Well-Being: Wetlands and Water; World Resources Institute: Washington, DC, USA, 2005.

2. Wang, Z.; Wu, J.; Madden, M.; Mao, D. China's wetlands: Conservation plans and policy impacts. Ambio 2012, 41, 782-786. [CrossRef] [PubMed]

3. Gao, J.; Li, X.; Brierley, G. Topographic influence on wetland distribution and change in Maduo County, Qinghai-Tibet Plateau, China. J. Mt. Sci. 2012, 9, 362-371. [CrossRef]

4. Niu, Z.; Zhang, H.; Wang, X.; Yao, W.; Zhou, D.; Zhao, K.; Zhao, H.; Li, N.; Huang, H.; Li, C.; et al. Mapping wetland changes in China between 1978 and 2008. Chin. Sci. Bull. 2012, 57, 2813-2823. [CrossRef]

5. Van Asselen, S.; Verburg, P.H.; Vermaat, J.E.; Janse, J.H. Drivers of wetland conversion: A global meta-analysis. PLoS ONE 2013, 8 , e81292. [CrossRef] [PubMed]

6. Brinson, M.M.; Malvárez, A.I. Temperate freshwater wetlands: Types, status, and threats. Environ. Conserv. 2002, 29, 115-133. [CrossRef]

7. Mitsch, W.J. Applying science to conservation and restoration of the world's wetlands. Water Sci. Technol. 2005, 51, 13-26. [CrossRef] [PubMed]

8. Huang, N.; Wang, Z.; Liu, D.; Niu, Z. Selecting sites for converting farmlands to wetlands in the Sanjiang Plain, Northeast China, based on remote sensing and GIS. Environ. Manag. 2010, 46, 790-800. [CrossRef]

9. Intergovernmental Panel on Climate Change. Summary for policymakers. In Climate Change 2007: The Physical Science Basis. Contribution of Working Group I to the Fourth Assessment Report of the Intergovernmental Panel on Climate Change; Cambridge University Press: New York, NY, USA, 2007.

10. Lin, W.; Zhang, L.; Du, D.; Yang, L.; Lin, H.; Zhang, Y.; Li, J. Quantification of land use/land cover changes in Pearl River Delta and its impact on regional climate in summer using numerical modeling. Reg. Environ. Chang. 2009, 9, 75-82. [CrossRef]

11. Seidl, A.F.; Moraes, A.S. Global valuation of ecosystem services: Application to the Pantanal da Nhecolandia, Brazil. Ecol. Econ. 2000, 33, 1-6. [CrossRef]

12. Wang, G.; Li, H.; An, M.; Ni, J.; Ji, S.; Wang, J. A regional-scale consideration of the effects of species richness on above-ground biomass in temperate natural grasslands of China. J. Veg. Sci. 2011, 22, 414-424. [CrossRef]

13. Fang, J.; Chen, A.; Peng, C.; Zhao, S.; Ci, L. Changes in forest biomass carbon storage in China between 1949 and 1998. Science 2001, 292, 2320-2322. [CrossRef] [PubMed]

14. Fang, J.Y.; Wang, G.G.; Liu, G.H.; Xu, S.L. Forest biomass of China: An estimate based on the biomass-volume relationship. Ecol. Appl. 1998, 8, 1084-1091. [CrossRef]

15. Zhang, Y.; Liang, S. Changes in forest biomass and linkage to climate and forest disturbances over Northeastern China. Glob. Chang. Biol. 2014, 20, 2596-2606. [CrossRef] [PubMed]

16. Dixon, R.K. Carbon pools and flux of global forest ecosystems. Science 1994, 263, 185-190. [CrossRef] [PubMed]

17. Hu, T.; Su, Y.; Xue, B.; Liu, J.; Zhao, X.; Fang, J.; Guo, Q. Mapping global forest aboveground biomass with spaceborne LiDAR, optical imagery, and forest inventory data. Remote Sens. 2016, 8, 565. [CrossRef]

18. Granier, A.; Loustau, D.; Bréda, N. A generic model of forest canopy conductance dependent on climate, soil water availability and leaf area index. Ann. For. Sci. 2000, 57, 755-765. [CrossRef]

19. Hayakawa, A.; Shimizu, M.; Woli, K.P.; Kuramochi, K.; Hatano, R. Evaluating stream water quality through land use analysis in two grassland catchments: Impact of wetlands on stream nitrogen concentration. J. Environ. Qual. 2006, 35, 617-627. [CrossRef] [PubMed] 
20. Granier, A.; Reichstein, M.; Breda, N.; Janssens, I.A.; Falge, E.; Ciais, P.; Grünwald, T.; Aubinet, M.; Berbigier, P.; Bernhofer, C.; et al. Evidence for soil water control on carbon and water dynamics in European forests during the extremely dry year: 2003. Agric. For. Meteorol. 2007, 143, 123-145. [CrossRef]

21. Brooks, J.R.; Meinzer, F.C.; Coulombe, R.O.B.; Gregg, J. Hydraulic redistribution of soil water during summer drought in two contrasting Pacific Northwest coniferous forests. Tree Physiol. 2002, 22, 1107-1117. [CrossRef]

22. Gao, Y.; Lu, D.; Li, G.; Wang, G.; Chen, Q.; Liu, L.; Li, D. Comparative analysis of modeling algorithms for forest aboveground biomass estimation in a subtropical region. Remote Sens. 2018, 10, 627. [CrossRef]

23. Tan, K.; Piao, S.; Peng, C.; Fang, J. Satellite-based estimation of biomass carbon stocks for northeast China's forests between 1982 and 1999. For. Ecol. Manag. 2007, 240, 114-121. [CrossRef]

24. Ren, H.; Qin, H.; Ouyang, Z.; Wen, X.; Jin, X.; Liu, H.; Lu, H.; Liu, H.; Zhou, J.; Zeng, Y.; et al. Progress of implementation on the Global Strategy for Plant Conservation in (2011-2020) China. Biol. Conserv. 2019, 230, 169-178. [CrossRef]

25. Chen, H.Y.; Vasiliauskas, S.; Kayahara, G.J.; Ilisson, T. Wildfire promotes broadleaves and species mixture in boreal forest. For. Ecol. Manag. 2009, 257, 343-350. [CrossRef]

26. Mutanga, O.; Adam, E.; Cho, M.A. High density biomass estimation for wetland vegetation using WorldView-2 imagery and random forest regression algorithm. Int. J. Appl. Earth Obs. Geoinf. 2012, 18, 399-406. [CrossRef]

27. Zhu, W.; Cao, G.; Li, Y.; Xu, W.; Shi, M.; Qin, L. Evaluation of river ecosystem health in tumen River Basin. Acta Oecologica 2014, 14, 3969-3977. (In Chinese)

28. Tootchi, A.; Jost, A.; Ducharne, A. Multi-source global wetland maps combining surface water imagery and groundwater constraints. Earth Syst. Sci. Data 2019, 11, 189-220. [CrossRef]

29. Zhang, J.; Zheng, Y.; Qi, D.; Li, R.; Yi, X. DNN-based prediction model for spatio-temporal data. In Proceedings of the 24th ACM SIGSPATIAL International Conference on Advances in Geographic Information Systems, Burlingame, CA, USA, 31 October-3 November 2016; pp. 1-4.

30. Jiapaer, G.; Chen, X.; Bao, A. A comparison of methods for estimating fractional vegetation cover in arid regions. Agric. For. Meteorol. 2011, 151, 1698-1710. [CrossRef]

31. Rumney, G.R. Climatology and the World's Climates; The Macmillan Company: New York, NY, USA, $1968 ;$ pp. 187-206.

32. Fang, J.; Piao, S.; Zhou, L.; He, J.; Wei, F.; Myneni, R.B.; Tucker, C.J.; Tan, K. Precipitation patterns alter growth of temperate vegetation. Geophys. Res. Lett. 2005, 32. [CrossRef]

33. Stegen, J.C.; Swenson, N.G.; Enquist, B.J.; White, E.P.; Phillips, O.L.; Jørgensen, P.M.; Weiser, M.D.; Monteagudo Mendoza, A.; Núñez Vargas, P. Variation in above-ground forest biomass across broad climatic gradients. Glob. Ecol. Biogeogr. 2011, 20, 744-754. [CrossRef]

34. Shen, X.; Liu, B.; Jiang, M.; Lu, X. Marshland loss warms local land surface temperature in China. Geophys. Res. Lett. 2020, 47, e2020GL087648. [CrossRef]

35. Zheng, X.J.; Sun, P.; Zhu, W.H.; Xu, Z.; Fu, J.; Man, W.D.; Li, H.L.; Zhang, J.; Qin, L. Landscape dynamics and driving forces of wetlands in the Tumen River Basin of China over the past 50 years. Landsc. Ecol. Eng. 2017, 13, 237-250. [CrossRef]

36. Xiang, H.; Jia, M.; Wang, Z.; Li, L.; Mao, D.; Zhang, D.; Cui, G.; Zhu, W. Impacts of land cover changes on ecosystem carbon stocks over the transboundary Tumen River Basin in Northeast Asia. Chin. Geogr. Sci. 2018, 28, 973-985. [CrossRef] 